\title{
Maleic acid and succinic acid in fermented alcoholic beverages are the stimulants of gastric acid secretion
}

\author{
Stephan Teyssen, Gloria González-Calero, Michael Schimiczek, \\ and Manfred V. Singer \\ Department of Medicine IV (Gastroenterology), University Hospital of Heidelberg at Mannheim, 68135 Mannheim, Germany \\ Address correspondence to: Manfred V. Singer, Department of Medicine IV (Gastroenterology), University Hospital of Heidelberg \\ at Mannheim,Theodor-Kutzer-Ufer, 68135 Mannheim, Germany. Phone: 49-621-383-3284; \\ Fax: 49-621-383-3805; E-mail: Manfred.V.Singer@Med4.Ma.Uni-Heidelberg.de
}

Received for publication April 3, 1998, and accepted in revised form January 19, 1999.

\begin{abstract}
Alcoholic beverages produced by fermentation (e.g., beer and wine) are powerful stimulants of gastric acid output and gastrin release in humans. The aim of this study was to separate and specify the gastric acid stimulatory ingredients in alcoholic beverages produced by fermentation. Yeast-fermented glucose was used as a simple model of fermented alcoholic beverages; it was stepwise separated by different methods of liquid chromatography, and each separated solution was tested in human volunteers for its stimulatory action on gastric acid output and gastrin release. Five substances were detected by high-performance liquid chromatography and were analyzed by mass spectrometry and $1 \mathrm{H}-13 \mathrm{C}$ nuclear magnetic resonance spectroscopy. At the end of the separation process of the five identified substances, only the two dicarboxylic acids, maleic acid and succinic acid, had a significant $(P<0.05)$ stimulatory action on gastric acid output ( $76 \%$ and $70 \%$ of fermented glucose, respectively), but not on gastrin release. When given together, they increased gastric acid output by $100 \%$ of fermented glucose and by $95 \%$ of maximal acid output. We therefore conclude that maleic acid and succinic acid are the powerful stimulants of gastric acid output in fermented glucose and alcoholic beverages produced by fermentation, and that gastrin is not their mediator of action.
\end{abstract}

J. Clin. Invest. 103:707-713 (1999)

\section{Introduction}

Only during the last 15 years have systematic and controlled studies on the action of pure ethanol and some commonly ingested alcoholic beverages on gastric acid secretion and release of gastrin in humans been published $(1-8)$. Pure ethanol in low concentrations $(\leq 4 \% \mathrm{vol} / \mathrm{vol})$ is a mild stimulant of gastric acid output, whereas at higher concentrations, it has either no effect or a mildly inhibitory one (5). Alcoholic beverages with low ethanol content (beer and wine) are powerful stimulants of gastric acid output and gastrin release; the effect of beer is equal to the maximal acid output (5-8). Beverages with a higher ethanol content (e.g., whisky, gin, cognac) do not stimulate gastric acid output or release of gastrin $(5,7)$.

The ethanol content in beer $(4 \% \mathrm{vol} / \mathrm{vol})$ and wine $(10 \% \mathrm{vol} / \mathrm{vol})$ can be only partially or not at all responsible for the marked gastric acid secretory responses to beer and wine. Thus, nonalcoholic ingredients in beer or wine are most likely responsible for the stimulatory gastric action of these alcoholic beverages. The intensive search for the stimulatory substances in beer has proved that none of the known nonalcoholic stimulants of gastric acid output present in beer either alone or in combination can be implicated (6).

In a recent study (7), we reported that alcoholic beverages produced by fermentation (such as beer, wine, champagne, and sherry), but not by distillation (such as whisky, cognac, calvados, armagnac, Bacardi, Pernod, Cointreau, and Campari), are powerful stimulants of gastric acid output and release of gastrin. In addition, we found that the alcoholic beverage constituents that stimulate gastric acid output and release of gastrin are produced during the process of fermentation and removed during the following process of distillation (7).

We used yeast-fermented glucose as a simpler model of beer in order to look for the powerful stimulants of gastric acid output produced during the process of alcoholic fermentation $(6,9)$. Alcoholic fermentation is the catabolism of glucose to pyruvate (e.g., glycolysis) and of pyruvate to ethanol by yeast. Yeast-fermented glucose $(11.5 \%$ $w t / v o l)$ has been shown to mimic the effects of beer on gastric acid output and release of gastrin $(6,9)$. Whereas beer has a great number of unknown substances, yeastfermented glucose is a relatively pure solution.

The aim of the present investigation was to separate and identify the substances in fermented glucose and alcoholic beverages that are responsible for their powerful stimulatory action on gastric acid output and release of gastrin in nonalcoholic healthy humans.

\section{Methods}

\section{Subjects}

Thirty-five healthy young male $(n=20)$ and female $(n=15)$ volunteers (age, 21-37 years; body weight, $50-87 \mathrm{~kg}$ ) were studied. All subjects were in good health and had a normal physical examination, electrocardiogram, and laboratory tests, including blood count, platelets, prothrombin time, aspartate aminotransferase, alanine aminotransferase, $\gamma$-glutamyltransferase, amylase, lipase, creatinine, electrolytes, glucose, and urine analysis. All took no medication, and either did not drink at all 


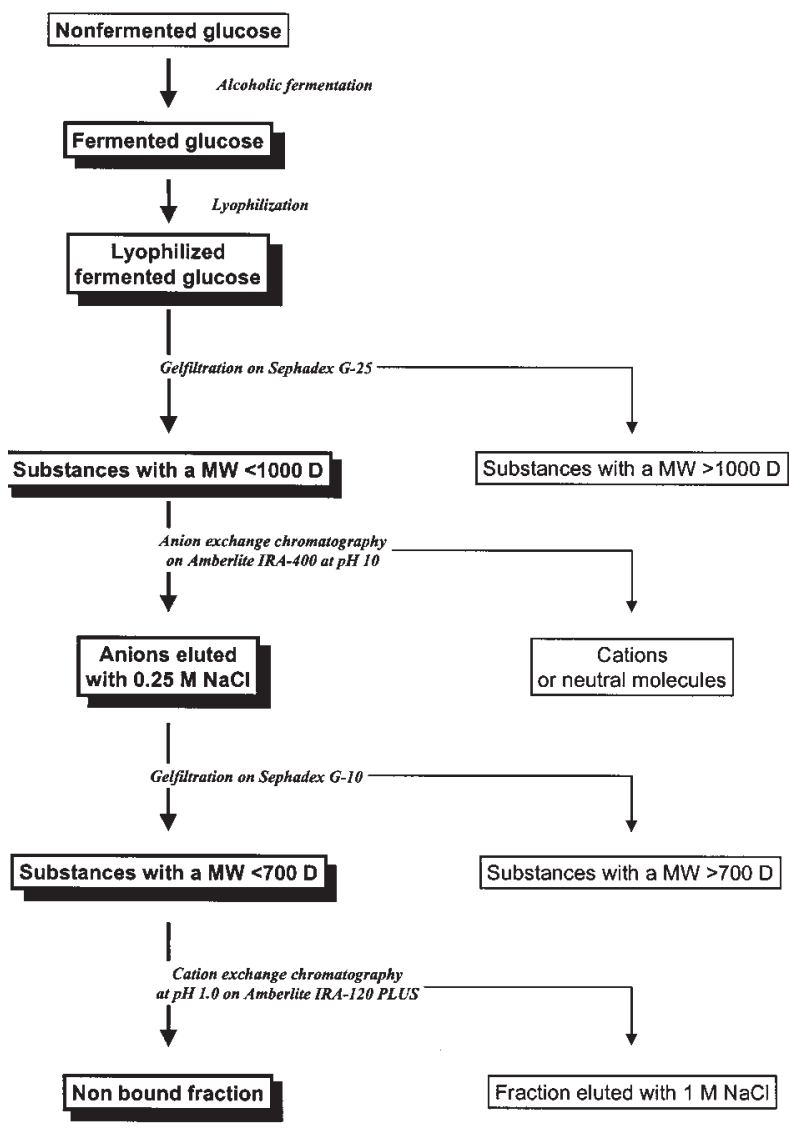

Figure 1

Schematic representation of the protocol of the separation process: part I. The shadowed and bordered test solutions significantly $(P<0.05)$ stimulated gastric acid output.

or drank less than $20 \mathrm{~g}$ of pure alcohol each day. Twenty-five percent were smokers (not more than 10 cigarettes per day). None of the volunteers was Helicobacter pylori-positive (tested by a $\left[{ }^{13} \mathrm{C}\right]$ urea breath test) $(10)$.

Each subject was investigated several times on separate days. Each of the test solutions listed in Table 1 was studied in six to 10 subjects; fermented glucose was tested in all subjects. All subjects underwent the control studies with isotonic glucose, and 29 subjects had a pentagastrin test for determination of the maximal acid output. The sequence of tests was randomized, and no more than two tests per week were performed in each subject, with a minimum interval of $48 \mathrm{~h}$ between the tests. Fully informed written consent was obtained from each subject, and the research protocol was approved by the Ethics Committee of the University Hospital of Heidelberg at Mannheim. The investigation was carried out according to the principles of the revised Declaration of Helsinki 1989.

\section{Protocol}

Test meal-stimulated gastric acid output. Gastric acid output in response to various liquid test meals was determined by automatic intragastric titration to $\mathrm{pH} 5.5$ with $0.5 \mathrm{M} \mathrm{NaOH}$ as described previously (11), with slight modifications $(12,13)$. After an overnight fast (12 h), during which the subjects also avoided smoking, a two-luminal nasogastric tube (AN 10; H.G. Anderson Products Inc., New York, New York, USA) was positioned in the most dependent part of the stomach. The position was controlled by the water-recovery test described by Hassan and Hobsley (14). The subjects were sitting in a slight- ly recumbent position. At the beginning of each experiment, the stomach was rinsed with water $(100-150 \mathrm{ml})$ and emptied by aspiration. Five hundred milliliters of isotonic glucose (control solution) was instilled intragastrically over $2 \mathrm{~min}$; intragastric titration was then started.

On each experimental day, six liquid meals (volume, $500 \mathrm{ml}$ each; $\mathrm{pH}$ 5.5) were instilled into the stomach in 30-min intervals. After each period, the remaining gastric content was emptied and the volume was measured. Thereafter, the next meal was instilled. The first two meals of each study consisted of isotonic glucose $(5.76 \% \mathrm{wt} / \mathrm{vol})$, which has been shown to inhibit gastric emptying without altering the acid-secretory response (12). Sufficient volume thus remained in the stomach for constant intragastric titration. Thereafter, $2 \times 500 \mathrm{ml}$ of one of the liquid test meals (Table 1 ) or control solutions (Table 3) (15) was instilled into the stomach, and acid secretion was measured for two 30-min periods.

To investigate the effect of the liquid test meals after ending perfusion, the actual test period was followed by two control periods in which isotonic glucose was administered for $30 \mathrm{~min}$ each (data not shown).

Blood samples $(5 \mathrm{ml})$ for determination of gastrin were drawn at 15-min intervals during the control periods and during administration of the test solutions. The blood was collected in ice-chilled ethylenediaminetetraacetic acid tubes containing $400 \mathrm{KIU}$ aprotinin (Trasylol, Bayer Corporation, Leverkusen, Germany) per $\mathrm{ml}$ of blood. The samples were centrifugated immediately at $4^{\circ} \mathrm{C}$, and the plasma was frozen at $-20^{\circ} \mathrm{C}$. Plasma gastrin was measured using a specific radioimmunoassay (Becton Dickinson and Co., Orangeburg, New York, USA). Assay precision was determined $(n=20)$ as intra-assay variation, which ranged from $2.59 \% \mathrm{SD}$ to $9.56 \% \mathrm{SD}$, and interassay variation, which ranged from $5.91 \%$ SD to $16.8 \%$ in a gastrin 17-I concentration range from $56.0 \mathrm{pg} / \mathrm{ml}$ to 474 $\mathrm{pg} / \mathrm{ml}$. Sensitivity was $3.3 \mathrm{pg} / \mathrm{ml}$, measured as the smallest concentration of gastrin 17-I that can be distinguished statistically from the mean binding sero standard $(\mathrm{B} 0+3 \mathrm{SD})$. Molar cross-reactivities with various forms of human gastrin are $100 \%$ for gastrin $17-I$ and $77 \%$ for gastrin II.

Pentagastrin-stimulated gastric acid output. To determine the maximal acid output (MAO) and to ensure that gastric acid output was within normal limits (i.e., that the subjects were neither hyposecretors nor hypersecretors), a pentagastrin test $(6 \mu \mathrm{g} / \mathrm{kg}$ subcutaneously) was performed in each subject. Gastric acid output was measured by intragastric titration. During the $60-\mathrm{min}$ basal period, two meals of isotonic glucose solution $(500 \mathrm{ml}$ each) were administered intragastrically. After subcutaneous exogenous administration of pentagastrin, another two isotonic glucose solutions were administered at 30-min intervals.

\section{Test and control solutions}

Before instillation of the liquid test and control solutions $(2 \times 500 \mathrm{ml}$ each; Tables 1 and 3$)$, the $\mathrm{pH}$ of each solution was adjusted to 5.5 by addition of $\mathrm{HCl}$ or $\mathrm{NaOH}$ in the appropriate amount. All given test solutions were separated from lyophilized fermented glucose as described in the next section. The separated and detected ingredients of fraction A (Table 1 and Fig. 3) at the end of the separation process of fermented glucose were given in concentrations and amounts found in finished beer (16).

Three different concentrations of glucose were tested: $(a)$ isotonic glucose (5.76\% wt/vol; control) (15); (b) nonfermented glucose $(11.5 \% \mathrm{wt} / \mathrm{vol})$; and $(c)$ fermented glucose $(11.5 \%$ $\mathrm{wt} / \mathrm{vol}$ ). The $11.5 \%$ (wt/vol) glucose concentration was used for fermentation because it is equal to the concentration of barley extract in finished wort. Alcoholic fermentation is the catabolism of glucose to pyruvate (e.g., glycolysis) and of pyruvate to ethanol by yeast. 


\section{Table 1}

One-hour incremental gastric acid output in response to the different separated ingredients of fermented glucose $(11.5 \% \mathrm{wt} / \mathrm{vol})$

$\begin{array}{lcc}\text { Test solution } & \begin{array}{c}\text { One-hour incremental } \\ \text { gastric acid output } \\ (\mathrm{mmol} / \mathrm{h})\end{array} & \begin{array}{c}\text { Percent of } \\ \text { fermented } \\ \text { glucose }\end{array} \\ \begin{array}{l}17.1 \pm 1.0^{\mathrm{A}} \\ \text { Fermented glucose }(n=35)\end{array} & 100.0 \\ \begin{array}{l}\text { Lyophilized fermented } \\ \text { glucose }(n=9)\end{array} & 100.6 \\ \begin{array}{l}\text { Separated ingredients of } \\ \text { lyophilized fermented glucose }\end{array} & 1.8 \pm 1.2 & \\ \begin{array}{l}\text { Mol wt }>1,000 \\ \text { Mol wt }<1,000\end{array} & 17.5 \pm 2.1^{\mathrm{A}} & 10.5 \\ \text { Cations and neutral substances } & & 102.3 \\ \text { with a mol wt }<1,000 & 1.7 \pm 1.4 & 9.9\end{array}$

Anions eluted with

$0.25 \mathrm{M} \mathrm{NaCl}$ and with a:

Mol wt $<1,000$

Mol wt $<700$

Mol wt $<700$ at $\mathrm{pH} 1.0$

$17.8 \pm 2.5^{\mathrm{A}}$

$12.4 \pm 1.2^{\mathrm{A}}$

104.1

72.5

Anions eluted with $0.25 \mathrm{M} \mathrm{NaCl}$

with a mol wt $<700$ at $\mathrm{pH} 1.0$

and their three fractions

Fraction I

$0.4 \pm 1.0$

$1.6 \pm 1.5$

$12.7 \pm 3.3^{\mathrm{A}}$

2.3

Fraction III

Three fractions of fraction III

Fraction A

Fraction B

Fraction $\mathrm{C}$

$10.0 \pm 1.6^{\mathrm{A}}$

$0.7 \pm 0.4$

$1.5 \pm 0.5$

4.1

8.8

Mixture of acetic acid, oxalic acid, L(+)-lactic acid,

maleic acid, and succinic acid

$16.9 \pm 2.7^{\mathrm{A}}$

98.8

Acetic acid $(200 \mathrm{mg} / \mathrm{l})^{\mathrm{B}}$

Oxalic acid $(12 \mathrm{mg} / \mathrm{l})^{\mathrm{B}}$

$\mathrm{L}(+)$-lactic acid $(100 \mathrm{mg} / \mathrm{l})^{\mathrm{B}}$

Maleic acid $(110 \mathrm{mg} / \mathrm{I})^{\mathrm{B}}$

Succinic acid $(16 \mathrm{mg} / \mathrm{l})^{\mathrm{B}}$

Maleic acid + succinic acid $(n=10)^{\mathrm{B}}$

$\begin{array}{cc}0.7 \pm 1.0 & 4.1 \\ 0.2 \pm 2.1 & 1.2 \\ 2.1 \pm 1.4 & 12.3 \\ 13.0 \pm 2.7^{\mathrm{A}} & 76.0 \\ 12.0 \pm 1.4^{\mathrm{A}} & 70.2 \\ 17.1 \pm 1.6^{\mathrm{A}} & 100.0\end{array}$

Results are means \pm SEM of six subjects if not stated otherwise. For a detailed description of the separation of the test solutions, see the text and Figs. 1 and 2. AP $<0.05$ compared with isotonic glucose $(n=35$; see Table 3$)$.

${ }^{B}$ Given in the concentration and amounts found in finished beer (16).

\section{Methods used for separation}

For the search and separation of the powerful stimulants of gastric acid output present in fermented glucose, different physicochemical methods had to be applied. In Figs. 1 and 2, a schematic representation of the steps of separation with the different liquid chromatography methods and the obtained test solutions is given.

Because fermented glucose contains a considerable amount of volatile substances, the first step of separation was the lyophilization of fermented glucose. Lyophilized fermented glucose was used for all performed steps of separation, such as gel filtration on Sephadex G-25, anion exchange chromatography of separated substances with a molecular weight (mol wt) $<1,000$ on Amberlite IRA-400 at $\mathrm{pH} 10.0$ and further purification of the stimulatory anions with $0.25 \mathrm{~N} \mathrm{NaCl}$, gel filtration of these anions on Sephadex G-10, and cation exchange of the separated anions with a mol wt $<700$ at $\mathrm{pH} 1.0$ on Amberlite IRA-120 PLUS.

The fraction that was not bound on Amberlite IRA-120 PLUS exerted a potent stimulatory action on gastric acid secretion and was separated into three fractions by anion exchange chromatography at pH 5.5 on Amberlite IRA-400. The anions were eluted selectively by a decreasing $\mathrm{pH}$-gradient ( $\mathrm{pH} 4.0$ to 1.0). Only the fraction that eluted between $\mathrm{pH} 2.0$ and 1.0 had a potent stimulatory effect on gastric acid output and was gel-filtrated on Sephadex G-10. Only one (fraction A) of three obtained fractions had a stimulatory action on gastric acid output.

This highly purified solution (fraction A) was further purified by HPLC on a Shodex KC-811 column by ion exclusion chromatography at a flow rate of $1 \mathrm{ml} / \mathrm{min}$ using $3 \mathrm{mM} \mathrm{HCIO}_{4}$ $(\mathrm{pH} 2.6)$ at $50^{\circ} \mathrm{C}$. Fraction A could be separated into six peaks (Fig. 3). Five of them were identical to acetic acid, oxalic acid, $\mathrm{L}(+)$-lactic acid, maleic acid, and succinic acid when compared against synthetic standards. Each separated solution of the six peaks of HPLC was analyzed by analytic mass spectrometry and ${ }^{1} \mathrm{H}-{ }^{13} \mathrm{C}$ nuclear magnetic resonance spectroscopy, and the obtained spectra were compared with standard spectra of the five substances separated by HPLC. All five substances found by HPLC could be confirmed. Peak 4 of HPLC (Fig. 3) consisted of a mixture of low-molecular-weight compounds, as judged by mass spectral analysis. It was impossible to separate these compounds by the chromatographic methods described here. Thus, it was impossible to identify these compounds by ${ }^{1} \mathrm{H}^{-13} \mathrm{C}$ nuclear magnetic resonance spectroscopy.

\section{Calculations and statistics}

All statistical analyses were performed on incremental responses, i.e., on observed gastric acid response minus response to intragastric isotonic glucose. To calculate the 1-h incremental gastric acid output, the value obtained during the second 30 min control period of intragastric glucose administration was multiplied by two, and this value was subtracted from the observed 1-h gastric acid response to a given stimulus. This 1-h incremental gastric acid output in response to the various test substances was calculated for each experiment and each subject, and these individual values were used for statistical analysis.

MAO was calculated by adding the two 30 -min outputs produced by subcutaneous injection of pentagastrin. The term $\max$ imal acid output describes the highest secretory response attainable with any dose of hormone, with higher doses producing no further increase. The maximal acid output is an indirect estimate of the total population of functional parietal cells in the stomach. To compare the gastric acid response to pentagastrin with that to the different test meals, the incremental MAO, i.e., observed MAO in response to pentagastrin minus acid output during intragastric instillation of isotonic glucose, was calculated.

The integrated gastrin response for each dose of stimulant was calculated by the formula described by Eysselein et al. (17). All statistical analyses were performed on the integrated responses of gastrin.

The differences between the test and control solutions within the different treatments were evaluated using the parametric $t$ test for paired values; for differences between the various treatments, the $t$ test for nonpaired values was used. $P<0.05$ was considered significant. Data are reported as means \pm SEM of six subjects unless stated otherwise.

\section{Results}

None of the subjects was a hypo- or hypersecretor. The mean basal gastric acid output in response to isotonic glucose (control solution) was $10.2 \pm 1.0 \mathrm{mmol} / \mathrm{h}(n=35)$. The mean MAO in response to pentagastrin was $28.3 \pm 1.3$ 
Table 2

One-hour integrated plasma gastrin response in response to the different separated ingredients of fermented glucose $(11.5 \% \mathrm{wt} / \mathrm{vol})$

$\begin{array}{lcc}\text { Test solution } & \begin{array}{c}\text { Integrated plasma } \\ \text { gastrin response } \\ (\mathrm{pM} / \mathrm{h})\end{array} & \begin{array}{c}\text { Percent of } \\ \text { fermented } \\ \text { glucose }\end{array} \\ \text { Fermented glucose }(n=23) & 3,317 \pm 323^{\mathrm{A}} & 100.0 \\ \text { Lyophilized fermented glucose }(n=9) & 1,805 \pm 603^{\mathrm{A}} & 54.4\end{array}$

Separated ingredients of

lyophilized fermented glucose

Mol wt $>1,000$

Mol wt $<1,000$

$-105 \pm 242$

$2,485 \pm 825^{\mathrm{A}}$

$-3.2$

74.9

Cations and neutral

substances with a

mol wt $<1,000$

$68 \pm 98$

2.1

Anions eluted with

$0.25 \mathrm{M} \mathrm{NaCl}$ and with a:

Mol wt $<1,000$

Mol wt $<700$

Mol wt $<700$ at $\mathrm{pH} 1.0$

$2,732 \pm 887^{A}$

82.4

$2,360 \pm 723^{\mathrm{A}} \quad 71.1$

$1,906 \pm 310^{\mathrm{A}} \quad 57.5$

Anions eluted with $0.25 \mathrm{M} \mathrm{NaCl}$

with a mol wt $<700$ at $\mathrm{pH} 1.0$

and their three fractions

Fraction I

Fraction II

Fraction III

Three fractions of fraction III

Fraction $\mathrm{A}$

Fraction $\mathrm{B}$

Fraction $C$

Mixture of acetic acid, oxalic acid,

$\mathrm{L}(+)$-lactic acid, maleic acid, and:

Succinic acid $(n=10)$

Acetic acid $(200 \mathrm{mg} / \mathrm{l} ; n=10)^{\mathrm{B}}$

Oxalic acid $(12 \mathrm{mg} / \mathrm{l} ; n=10)^{\mathrm{B}}$

$\mathrm{L}(+)$-lactic acid $(100 \mathrm{mg} / \mathrm{l} ; n=10)^{\mathrm{B}}$

Maleic acid $(110 \mathrm{mg} / \mathrm{l} ; n=10)^{\mathrm{B}}$

Succinic acid $(16 \mathrm{mg} / \mathrm{l} ; n=10)^{\mathrm{B}}$

Maleic acid + succinic acid $(n=10)^{\mathrm{B}}$

$\begin{array}{cc}94 \pm 206 & 2.8 \\ 236 \pm 94 & 7.1 \\ 157 \pm 198 & 4.7\end{array}$

$\begin{array}{cl}36 \pm 32 & 1.1 \\ 119 \pm 273 & 3.6 \\ 181 \pm 129 & 5.5\end{array}$

Results are means \pm SEM of six subjects if not stated otherwise. For a detailed description of the separation of the test solutions, see the text and Figs. 1 and 2 . AP $<0.05$ compared with isotonic glucose $(n=35$; see Table 3$)$.

${ }^{\mathrm{B}}$ Given in the concentration and amounts found in finished beer (16)

$\mathrm{mmol} / \mathrm{h}$, and the mean incremental MAO was $18.0 \pm 0.8$ $\mathrm{mmol} / \mathrm{h}(n=29)$. Intragastric instillation of distilled water $(n=6)$ did not significantly alter basal gastric acid output.

The one-hour incremental gastric acid outputs and one-hour integrated plasma gastrin levels in response to the different liquid test and control meals are summarized in Tables 1, 2, and 3 and in Figs. 4 and 5.

Gastric acid output. Fermented glucose (11.5\% wt/vol) caused an increase in gastric acid output up to $95 \%$ of MAO $(n=35)$. Lyophilized fermented glucose $(n=9)$; substances with a mol wt $<1,000$; anions with a mol wt $<1,000$; anions with a mol wt $<700$; the nonbound fraction of anions on Amberlite IRA-120 PLUS (cation exchange resin) at $\mathrm{pH} 1.0$; the fraction III of this non- bound fraction eluted on Amberlite IRA-400 (anion exchange resin) between a $\mathrm{pH}$ gradient of 2.0 and 1.0 ; and the fraction A of fraction III on Sephadex G-10 significantly $(P<0.05)$ stimulated gastric acid output compared with control. Gastric acid output was increased by $56 \%-97 \%$ of incremental MAO and by $59 \%-102 \%$ of the response to fermented glucose (Tables 1 and 3; see schematic representation of the separation protocol in Figs. 1 and 2). All other given test solutions such as substances with a mol wt >1,000; cations; fractions I and II of the nonbound fraction of anions; and fraction $\mathrm{B}$ and $\mathrm{C}$ of fraction III (Table 1) had no effect on gastric acid output.

At the end of the separation process, the following five carboxylic and dicarboxylic acids were left: acetic acid, L(+)-lactic acid, oxalic acid, maleic acid, and succinic acid. Their mixture in the same concentrations as are present in beer (16) significantly stimulated gastric acid output compared with control. All acids together increased gastric acid output up to $94 \%$ of incremental MAO and $99 \%$ of the response to fermented glucose.

When tested separately, oxalic acid, acetic acid, and L(+)lactic acid had no stimulatory effect on gastric acid output. Maleic acid and succinic acid, however, significantly increased gastric acid output by $76 \%$ and $70 \%$, respectively, of fermented glucose (Figs. 2 and 4). When given together in the concentrations present in beer, maleic acid and succinic acid significantly increased gastric acid output by $95 \%$ of MAO and $100 \%$ of fermented glucose.

Plasma gastrin levels. Fermented glucose significantly increased plasma gastrin levels up to 2.6-fold compared with control. Its one-hour integrated plasma gastrin response was 3,317 $\mathrm{pM} / 1(n=23$; Tables 2 and $3)$. Lyophilized fermented glucose $(n=9)$; substances with a mol wt $<1,000$; anions with a mol wt $<1,000$; anions with a mol wt $<700$; and the nonbound fraction of anions on Amberlite IRA-120 PLUS (cation exchange resin) at $\mathrm{pH} 1.0$ significantly increased plasma gastrin concentrations up to 2.7-fold compared with control. Their one-hour integrated plasma gastrin responses were $54 \%-82 \%$ of that of fermented glucose (Tables 2 and 3; see schematic representation of the separation protocol in Figs. 1 and 2). Substances with a mol wt $>1,000$ and cations (Tables 2 and 3 ) had no effect on release of gastrin.

\section{Table 3}

One-hour incremental gastric acid output and 1-h integrated plasma gastrin response in response to the different control solutions (15)

\begin{tabular}{|c|c|c|}
\hline Test solution & $\begin{array}{l}\text { hour incremental } \\
\text { tric acid output } \\
(\mathrm{mmol} / \mathrm{h})\end{array}$ & $\begin{array}{l}\text { Integrated plasma } \\
\text { gastrin response } \\
(\mathrm{pM} / \mathrm{h})\end{array}$ \\
\hline Distilled water & $-0.3 \pm 0.6$ & $-30 \pm 48$ \\
\hline $\begin{array}{l}\text { Isotonic glucose } \\
(5.76 \% \text { wt/vol; } n=35)\end{array}$ & $0.2 \pm 0.4$ & $-106 \pm 165$ \\
\hline Glucose (11.5\% wt/vol) & $-1.4 \pm 1.0$ & $48 \pm 78$ \\
\hline $\begin{array}{l}\text { Pentagastrin-stimulated } \\
\text { secretion }(\mathrm{MAO}) \text { plus glucose } \\
(5.76 \% \text { wt/vol; } n=29)\end{array}$ & $18.0 \pm 0.8^{A}$ & - \\
\hline
\end{tabular}




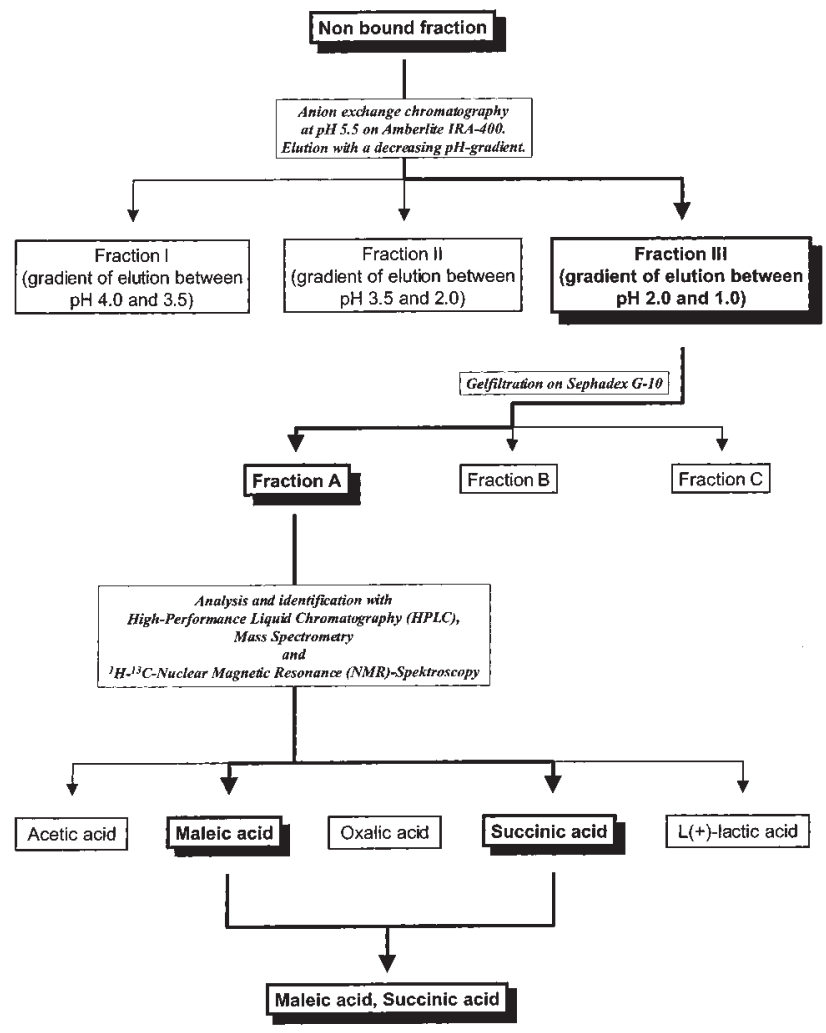

Figure 2

Schematic representation of the protocol of the separation process: part II. The shadowed and bordered test solutions significantly $(P<0.05)$ stimulated gastric acid output.

Plasma gastrin levels in response to fraction I to III of the nonbound fraction on Amberlite IRA-400 (anion exchange resin) and to the three fraction $\mathrm{A}$ to $\mathrm{C}$ of fraction III did not cause a significant increase in the onehour integrated plasma gastrin response (Tables 2 and 3 ).

The mixture of acetic acid, $\mathrm{L}(+)$-lactic acid, oxalic acid, maleic acid, and succinic acid in the same concentrations as are found in beer (16) did not cause a significant increase in the one-hour integrated plasma gastrin response (only $4 \%$ of that of fermented glucose; Tables 2 and 3 ).

When given singly, acetic acid, oxalic acid, L(+)-lactic acid, maleic acid, and succinic acid did not cause a significant increase in the one-hour integrated plasma gastrin response. The one-hour integrated plasma gastrin response to maleic acid and succinic acid together was not statistically significant ( $6 \%$ of that of fermented glucose; Tables 2 and 3, and Fig. 5).

\section{Discussion}

The new finding of the present investigation is that the dicarboxylic acids maleic acid and succinic acid are the powerful stimulants of gastric acid output in fermented glucose and most likely in alcoholic beverages produced by fermentation (e.g., beer and wine). They are able to stimulate gastric acid output as strong as that stimulated by beer, champagne, wine, and pentagastrin, without release of gastrin.

During the last 15 years, we have shown that alcoholic beverages produced by fermentation (e.g., beer and wine) but not by distillation (e.g., whisky and cognac) are powerful stimulants of gastric acid output and release of gastrin in humans. Neither their ethanol content nor the currently known nonalcoholic ingredients are responsible for this stimulatory action. The constituents that stimulate gastric acid output and release of gastrin are generated during the fermentation process and removed during the following process of distillation (2-7). The different actions of the various ethanol concentrations and the various alcoholic beverages prompted two obvious questions. Which nonalcoholic substances in beer and wine are responsible for the powerful stimulatory action of these two alcoholic beverages on gastric acid output and release of gastrin? Why do some alcoholic beverages stimulate gastric acid output and others not?

The experiments with the preproducts of finished beer clearly demonstrated that the addition of yeast to finished wort and the ensuing alcoholic fermentation are the essential steps for the generation of the stimulatory action of beer on the stomach $(6,9)$. This conclusion is further substantiated by our earlier experiments with fermented and nonfermented glucose $(6,9,18-23)$, as well as by the present experiments. Because yeast-fermented glucose mimics the effect of beer on gastric acid output and release of gastrin and is a relatively pure solution, fermented glucose was used in the present experiments for further separation of the stimulatory substances.

After many years of investigation, the separation process by its molecular weight and charge resulted in a highly pure solution that was analyzed with the method of highperformance liquid chromatography (HPLC), mass spectrometry, and ${ }^{1} \mathrm{H}^{-13} \mathrm{C}$ nuclear magnetic resonance spectroscopy for its ingredients. Of the five acids found, the two dicarboxylic acids, maleic acid and succinic acid,

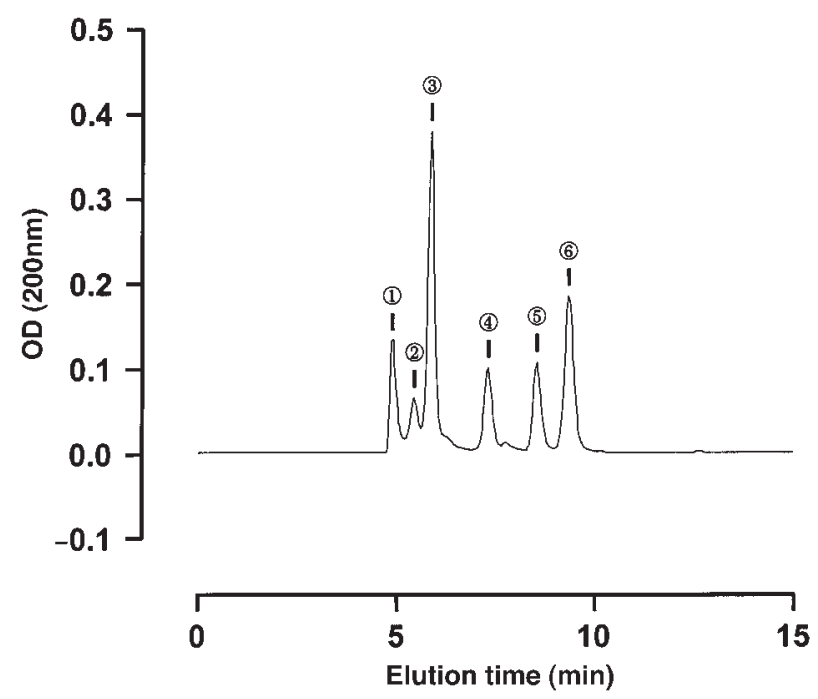

Figure 3

Ion exclusion chromatography (high-performance liquid chromatography) of fraction A (see Fig. 2 and text) on a Shodex KC-811 column (3 $\mathrm{mM} \mathrm{HClO}_{4}[\mathrm{pH} 2.6], 1 \mathrm{ml} / \mathrm{min}$ at $\left.50^{\circ} \mathrm{C}\right)$. Six "peaks" have been detected. Five of them were coincident with acetic acid, oxalic acid, $L(+)$-lactic acid, maleic acid, and succinic acid, and were compared with synthetic standards. Peak 4 has been classified as fragments by mass spectrometry and ${ }^{1} \mathrm{H}-{ }^{13} \mathrm{C}$ nuclear magnetic resonance spectroscopy. 


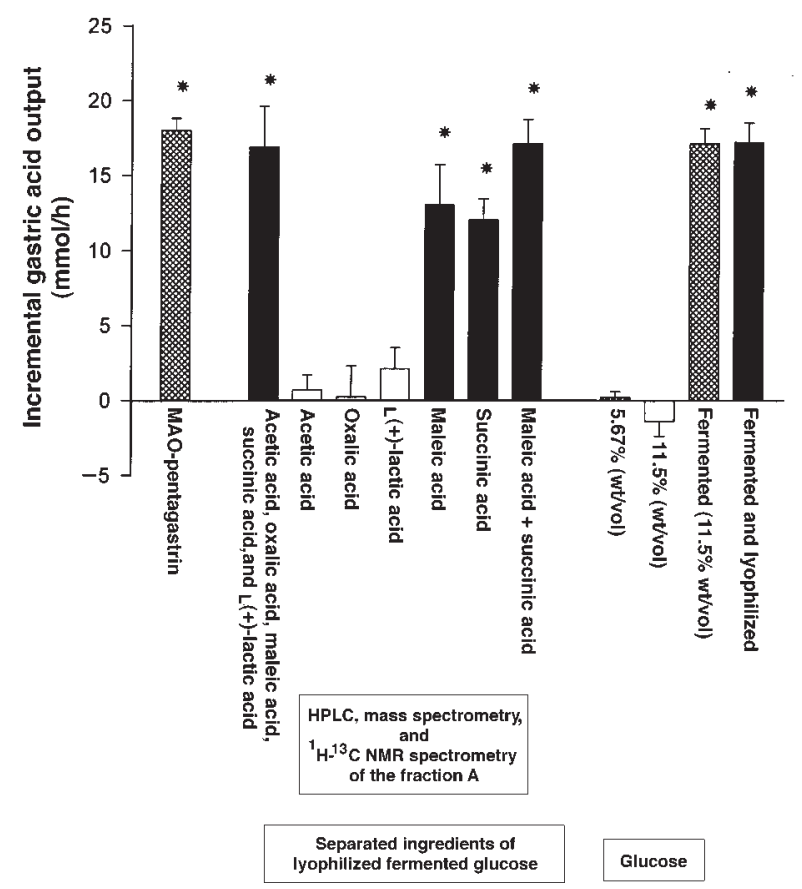

Figure 4

One-hour incremental gastric acid output (measured in $\mathrm{mmol}$ ) in response to different separated ingredients of lyophilized fermented glucose $(n=9)$. For comparison, the 1-h incremental maximal acid output $(M A O)$ in response to pentagastrin $(n=29)$ is also shown. Results are means \pm SEM of six subjects ( $n=10$ for maleic and succinic acid together). ${ }^{*} P<0.05$ compared with isotonic glucose $(n=35)$.

proved to be as potent as fermented glucose and pentagastrin in the stimulation of gastric acid output.

Maleic acid and succinic acid are chemically characterized as dicarboxylic acids with a $\mathrm{C}_{4}$-corpus. The three other detected acids lacking a stimulatory potency are either dicarboxylic (oxalic acid) or carboxylic acids [acetic acid and $\mathrm{L}(+)$-lactic acid)] with a $\mathrm{C}_{2}$-corpus (acetic acid and oxalic acid) or with a $\mathrm{C}_{3}$-corpus $[\mathrm{L}(+)$-lactic acid)]. We suppose that the length of the molecule $\left(\mathrm{C}_{4} \mathrm{vs} . \mathrm{C}_{3}\right.$ and $\mathrm{C}_{2}$ ) besides the two carboxylic groups is essential for the biologic activity of maleic acid and succinic acid on the parietal cells (e.g., stimulation of gastric acid secretion).

To our knowledge, until the present study, it was unknown whether maleic acid and succinic acid stimulated gastric acid output. Several possible mechanisms of action come to mind. Maleic acid and succinic acid may stimulate gastric acid output by a direct interaction with one of the known or an unknown receptors of the parietal cells and, if at all, only by small release of gastrin. To our knowledge, there exist no published data about the affinity of dicarboxylic acids such as maleic acid and succinic acid either to one of the known four receptors (acetylcholine, histamine, gastrin, and glucagon-like peptide-I) of the parietal cell or to the gastrin cells.

The action of maleic acid and succinic acid could be secondary to their lipid solubility, entry into the parietal cells, and subsequent intracellular events (e.g., release of $\mathrm{Ca}^{2+}$, stimulation of phosphatases) or to release of histamine from histamine-containing cells. In unpublished experiments conducted on isolated rat parietal cells (purity
$>95 \%$, we observed a dose-dependent stimulation of acid secretion by maleic and succinic acid, which was mediated by extracellular $\mathrm{Ca}^{2+}$ entry, suggesting the action of a membrane bound receptor. cAMP does not seem to play a major role in that action. Even the addition of 3-isobutyl-1methylxanthine (an inhibitor of cAMP phosphodiesterase) resulted in no stimulation of acid secretion (unpublished results). To clarify the hypothesis that the mechanism of action is due to a hitherto unknown receptor, radioligand binding studies are needed. Given the low content of enterochromaffine-like cells in our cell preparation $(<1 \%)$, the stimulating action of both acids is most likely independent of histamine release. Neither a $\mathrm{Ca}^{2+}$ release from intracellular stores nor the involvement of inositol phosphate turnover can be excluded. Studies using the fluorescent indicator fura- 2 and HPLC analysis of inositol phosphate metabolism remain to be conducted.

An interesting observation of the present investigation is that maleic acid and succinic acid do stimulate gastric acid output as strong as that of fermented glucose without causing a significant release of gastrin, whereas fermented glucose is also a powerful gastrin releaser. It is generally accepted that gastrin is the major hormonal mediator of the gastric acid response to nutrients. It is noteworthy that during the separation process the capacity of the different solutions of fermented glucose to release gastrin substantially decreased. Defining the gastrin response to fermented glucose as $100 \%$, lyophilized fermented glucose only caused a gastrin response of about $54 \%$, and maleic acid and succinic acid no longer caused a statistically significant increase in plasma gastrin levels. The potency to stimulate gastric acid output of these different test solutions, however, remained unchanged.

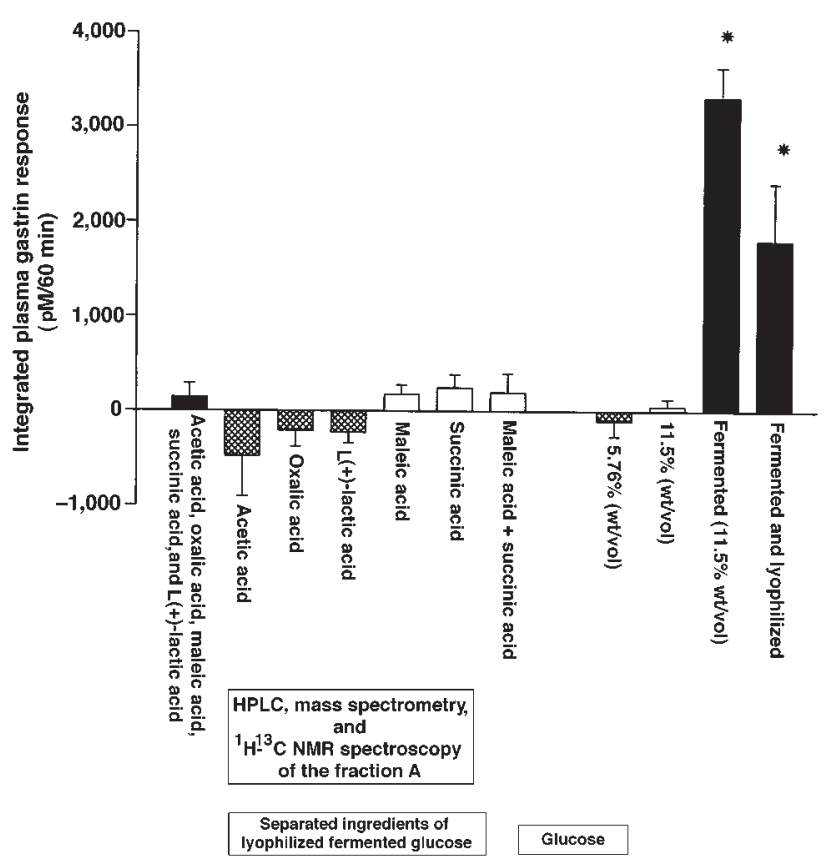

Figure 5

One-hour integrated plasma gastrin response (measured in $\mathrm{pM}$ ) in response to different separated ingredients of lyophilized fermented glucose $(n=9)$. Results are means \pm SEM of 10 subjects. ${ }^{*} P<0.05$ compared with isotonic glucose $(n=35)$. 
One possible explanation for the loss of the capacity to release gastrin is the loss of volatile substances during the lyophilization of fermented glucose. It is unlikely that nonvolatile substances such as calcium, magnesium, amines, phenols, amaroids, vitamins, organic acids, purines, and pyrimidines play a major role in the release of gastrin, as these ingredients of beer did not stimulate gastric acid output and release of gastrin when given alone or in combination in amounts and concentrations found in beer (6). The gastrin-releasing potency of fermented glucose was lost during the separation process of fraction I to III of the nonbound fraction on Amberlite IRA-400 (anion exchange resin). It seems that the gastrin-releasing ingredients of fraction I to III will have a potentiating effect on gastrin release when given together (test solution with anions eluted with $0.25 \mathrm{M} \mathrm{NaCl}$ and with a mol wt $<700$ at $\mathrm{pH}$ 1.0). Thus, unknown substances in beer are responsible for the strong release of gastrin by this alcoholic beverage, and the search for gastrin releaser in the different fractions will open a new field of research.

In conclusion, the dicarboxylic acids maleic acid and succinic acid are the powerful stimulants of gastric acid output in fermented glucose and in alcoholic beverages produced by fermentation (e.g., beer and wine). They are able to stimulate gastric acid output as strong as that produced by beer, champagne, wine, and pentagastrin (a powerful exogenous stimulus to induce MAO), but without gastrin being their mediator of action. Their mechanisms of action, as well as the unknown substances in fermented glucose that release gastrin, remain to be elucidated.

\section{Acknowledgments}

The authors thank Britta Spies, Tordis Lenzing, Klaus-Peter Spies, Jan Rabe, Dariusch Haghi, Markus Schäfer, Mario Schäff, and Dirk Hartmann for their collaboration in some of the experiments, and Annelen Korn for technical assistance during the experiments. The authors thank Rudolf L. Riepl (University Hospital of Munich, Munich, Germany) for determination of some plasma gastrin levels, and Richard Richerts and Martin Will (BASF, Ludwigshafen, Germany) for their collaboration in the performance of the mass spectrometry and $1 \mathrm{H}-13 \mathrm{C}$ nuclear magnetic resonance spectroscopy. The investigations were supported by grants from the Wilhelm-Sander Stiftung and the Forschungsfond der Fakultät für Klinische Medizin Mannheim der Universität Heidelberg.

1. McArthur, K., Hogan, D., and Isenberg, J.I. 1982. Relative stimulatory effects of commonly ingested beverages on gastric acid secretion in humans. Gastroenterology. 83:199-203.
2. Lenz, H.J., Ferrari-Taylor, J., and Isenberg, J.I. 1983. Wine and five percent ethanol are potent stimulants of gastric acid secretion in humans. Gastroenterology. 85:1082-1087.

3. Singer, M.V., Calden, H., Eysselein, V.E., and Goebell, H. 1983. Bier stimuliert sehr stark, seine Inhaltsstoffe Äthanol und Aminosäuren hingegen nur schwach die Magensäuresekretion des Menschen. Z. Gastroenterol. 21:439-440.

4. Singer, M.V., Eysselein, V.E., and Goebell, H. 1983. Beer and wine but not whisky and pure ethanol do not stimulate release of gastrin in humans. Digestion. 26:73-79.

5. Singer, M.V., Leffmann, C., Eysselein, V.E., Calden, H., and Goebell, H. 1987. Action of ethanol and some alcoholic beverages on gastric acid secretion and release of gastrin in humans. Gastroenterology. 93:1247-1254.

6. Singer, M.V., Teyssen, S., and Eysselein, V.E. 1991. Action of beer and its ingredients on gastric acid secretion and release of gastrin in humans. Gastroenterology. 101:935-942.

7. Teyssen, S., et al. 1997. Alcoholic beverages produced by fermentation but not by distillation are powerful stimulants of gastric acid secretion in humans. Gut. 40:49-56.

8. Chari, S.T., Teyssen, S., and Singer, M.V. 1993. Alcohol and gastric acid secretion in humans. Gut. 34:843-847.

9. Teyssen, S., Singer, M.V., and Eysselein, V.E. 1991. Fermentation of carbohydrates by yeast is the major step for the powerful stimulatory action of beer on gastric acid secretion in humans. Alcohol Alcohol. 26:261. (Abstr.)

10. Graham, D.Y., Klein, P.D., and Evans, D.J. 1987. Campylobacter pylori detected non-invasively by the ${ }^{13} \mathrm{C}$-urea breath test. Lancet. 1:1174-1177.

11. Fordtran, J.S., and Walsh, J.H. 1973. Gastric acid secretion rate and buffer content of the stomach after eating, results in normal subjects and in patients with duodenal ulcer. J. Clin. Invest. 52:645-657.

12. Maxwell, V., Eysselein, V.E., Kleibeuker, J., Reedy, T., and Walsh, J.H. 1984. Glucose perfusion and intragastric titration. Dig. Dis. Sci. 29:321-326.

13. Lam, S.K., Isenberg, J.I., Grossman, M.I., Lane, W.H., and Walsh, J.H. 1980. Gastric acid secretion is abnormally sensitive to endogenous gastrin released after peptone test meals in duodenal ulcer patients. J. Clin. Invest. 65:555-562.

14. Hassan, M.A., and Hobsley, M. 1970. Positioning of subject and of nasogastric tube during a gastric secretion study. Br. Med.J. 1:458-460.

15. Chari, S.T., Teyssen, S., and Singer, M.V. 1993. What controls should be used in studies of acute effects of alcohol and alcoholic beverages on the stomach and the pancreas? Scand. J. Gastroenterol. 28:289-295.

16. Piendl, A. 1980. Deutsches Pilsener Lagerbier, ein Lebens- und Genußmittel. Branwelt. 120:518-532.

17. Eysselein, V.E., Singer, M.V., Wentz, H., and Goebell, H. 1984. Action of ethanol on gastrin release in the dog. Dig. Dis. Sci. 29:12-18.

18. Teyssen, S., Spies, K.P., Schlattmann, B., and Singer, M.V. 1992. Beer and fermented glucose are powerful stimulants of gastric acid secretion in humans. Which metabolic product of glucose is responsible for this effect? Alcohol Alcohol. 27(Suppl. 1):45. (Abstr.)

19. Teyssen, S., González-Calero, G., Schäfer, M., Schäff, M., and Singer, M.V. 1993. Partial purification of the powerful stimulants of gastric acid secretion present in beer and fermented glucose. Alcohol Alcohol. 28:241. (Abstr.)

20. Teyssen, S., González-Calero, G., Brust, A., Rabe, J., and Singer, M.V. 1994. Which ingredients of beer and fermented glucose are responsible for their powerful action on gastric acid secretion in humans? Partial purification. Gastroenterology. 106:A196. (Abstr.)

21. Teyssen, S., González-Calero, G., Brust, A., Riepl, R.L., and Singer, M.V. 1994. Effect of some ingredients of beer and fermented glucose on gastric acid secretion and release of gastrin in humans. Alcoholism. 18:30A. (Abstr.)

22. Teyssen, S., González-Calero, G., Korn, A., and Singer, M.V. 1995. Organic carboxylic acids in beer and fermented glucose are the powerful stimulants of gastric acid output by these beverages-first results. Alcohol Alcohol. 30:523. (Abstr.)

23. Teyssen, S., González-Calero, G., Korn, A., and Singer, M.V. 1996. Organic carboxylic acids are the powerful stimulants of gastric acid output in beer and fermented glucose. Gastroenterology. 110:A277. (Abstr.) 